\title{
Article
}

\section{Enhanced Tissue Integration During Cartilage Repairln VitroCan Be Achieved by Inhibiting Chondrocyte Death at the Wound Edge}

Gilbert, Sophie J., Singhrao, Simarjit Kaur, Khan, Ilyas M., Gonzalez, Lee G., Thomson, Brian M., Burdon, Drew, Duance, Victor C. and Archer, Charles W.

Available at http://clok.uclan.ac.uk/7026/

Gilbert, Sophie J., Singhrao, Simarjit Kaur ORCID: 0000-0001-9573-5963, Khan, Ilyas M., Gonzalez, Lee G., Thomson, Brian M., Burdon, Drew, Duance, Victor C. and Archer, Charles W. (2009) Enhanced Tissue Integration During Cartilage Repairln VitroCan Be Achieved by Inhibiting Chondrocyte Death at the Wound Edge. Tissue Engineering Part A, 15 (7). pp. 1739-1749. ISSN 1937-3341

It is advisable to refer to the publisher's version if you intend to cite from the work. http://dx.doi.org/10.1089/ten.tea.2008.0361

For more information about UCLan's research in this area go to http://www.uclan.ac.uk/researchgroups/ and search for <name of research Group>.

For information about Research generally at UCLan please go to http://www.uclan.ac.uk/research/

All outputs in CLoK are protected by Intellectual Property Rights law, including Copyright law. Copyright, IPR and Moral Rights for the works on this site are retained by the individual authors and/or other copyright owners. Terms and conditions for use of this material are defined in the policies page. 


\title{
Enhanced Tissue Integration During Cartilage Repair In Vitro Can Be Achieved by Inhibiting Chondrocyte Death at the Wound Edge
}

\author{
Sophie J. Gilbert, Ph.D., ${ }^{1}$ Sim K. Singhrao, Ph.D., ${ }^{1}$ Ilyas M. Khan, Ph.D., ${ }^{1}$ \\ Lee G. Gonzalez, M.Sc., ${ }^{2}$ Brian M. Thomson, Ph.D., ${ }^{3}$ Drew Burdon, Ph.D., ${ }^{3}$ \\ Victor C. Duance, Ph.D., ${ }^{1}$ and Charles W. Archer, Ph.D. ${ }^{1}$
}

Objective: Experimental wounding of articular cartilage results in cell death at the lesion edge. The objective of this study was to investigate whether inhibition of this cell death results in enhanced integrative cartilage repair. Methods: Bovine articular cartilage discs $(6 \mathrm{~mm})$ were incubated in media containing inhibitors of necrosis (Necrostatin-1, Nec-1) or apoptosis (Z-VAD-FMK, ZVF) before cutting a $3 \mathrm{~mm}$ inner core. This core was left in situ to create disc/ring composites, cultured for up to 6 weeks with the inhibitors, and analyzed for cell death, sulfated glycosaminoglycan release, and tissue integration.

Results: Creating the disc/ring composites resulted in a significant increase in necrosis. ZVF significantly reduced necrosis and apoptosis at the wound edge. Nec-1 reduced necrosis. Both inhibitors reduced the level of wound-induced sulfated glycosaminoglycan loss. Toluidine blue staining and electron microscopy of cartilage revealed significant integration of the wound edges in disc/ring composites treated with ZVF. Nec-1 improved integration, but to a lesser extent. Push-out testing revealed that ZVF increased adhesive strength compared to control composites.

Conclusions: This study shows that treatment of articular cartilage with cell death inhibitors during wound repair increases the number of viable cells at the wound edge, prevents matrix loss, and results in a significant improvement in cartilage-cartilage integration.

\section{Introduction}

A RTICULAR CARTILAGE HAS a low intrinsic capacity for repair $^{1}$ with the repair response being impeded by a lack of integration of the repair tissue with the surrounding native cartilage. It is well established that wounding of articular cartilage leads to apoptotic and necrotic cell death at the lesion edge $\mathrm{e}^{2-7}$; thus, cartilage tissue integration is likely impaired by a lack of live or viable cells at the interface region that are capable of producing a functional repair tissue. ${ }^{8,9}$ In addition, this is hindered by the inherent limited ability of chondrocytes to migrate through the extracellular matrix toward the acellular interface region. ${ }^{9}$ Because surgical repair of cartilage lesions often requires debridement and/or reshaping of cartilage, associated chondrocyte death at the wound edges will be an inevitable problem. Historically, it has been reported that there is a distinct lack of integration of repair tissue with the surrounding host cartilage, with formation of chondrocyte clusters adjacent to zones of cartilage necrosis. ${ }^{10}$ Reindal et al. found that if bo- vine articular cartilage explants were cultured in partial apposition, an increase in adhesive strength was observed and that this was dependent on the presence of viable chondrocytes, and thus active cellular metabolism. ${ }^{11}$

Therefore, it is generally accepted that increasing the number of viable chondrocytes at the wound edge will promote tissue integration. ${ }^{4,8,9,11-13}$ Indeed, a number of studies have shown that enzymatic treatment increases cell density at the wound edges of cartilage explants and enhances integrative repair., ${ }^{9,13}$ Interestingly, recent studies have shown that short-term intra-articular administration of a potent caspase inhibitor (Z-VAD-FMK, ZVF) results in a decrease in chondrocyte apoptosis and subsequently less cartilage degeneration after experimental osteochondral injury in rabbits. ${ }^{14}$ Further, the use of apoptosis inhibitors in vivo reduced the number of cells undergoing apoptosis in cartilage that had been prepared for surgery, leading to the conclusions that cell death inhibitors could improve the results of cartilage repair surgery. ${ }^{15}$ In the light of these findings, we hypothesized that inhibition of the cell death

\footnotetext{
${ }^{1}$ Connective Tissue Biology Laboratories, School of Biosciences, Cardiff University, Cardiff, Wales, United Kingdom.

${ }^{2}$ School of Optometry \& Visual Sciences, Cardiff University, Cardiff, Wales, United Kingdom.

${ }^{3}$ Smith \& Nephew Research Centre, Heslington, York, United Kingdom.
} 
that occurs as a response to wounding of articular cartilage will result in enhanced cartilage integrative repair.

\section{Materials and Methods}

\section{Materials}

All chemicals were from Sigma (Poole, United Kingdom) unless otherwise stated, and were of analytical grade or above. Culture medium consisted of Dulbecco's modified Eagle's medium (1:1 mixture of DMEM-Glutamax- $\mathrm{I}^{\mathrm{TM}}$ and Hams F12 media) containing $10 \mathrm{mM}$ HEPES pH 7.4, $100 \mathrm{U} / \mathrm{mL}$ penicillin, $100 \mu \mathrm{g} / \mathrm{mL}$ streptomycin, and $50 \mu \mathrm{g} / \mathrm{mL}$ ascorbate-2-phosphate, and supplemented with $1 \times$ insulintransferrin-sodium selenite (Invitrogen, Paisley, United Kingdom). Insulin-transferrin-sodium selenite supplementation enables chondrocytes to maintain metabolism in serum-free conditions without loss of their normal phenotype as well as preventing activation of stress signaling pathways that occurs on the withdrawal of serum from culture media. ${ }^{16}$

\section{Disc/ring composite preparation and culture}

Articular cartilage from the metacarpophalangeal joint of immature bovine steers, in the form of circular explants, was used to simulate cartilage-cartilage integration in this study. For each experiment, cartilage was taken from a minimum of four legs and randomly assigned to a treatment group. Fulldepth cartilage discs (mean depth $2.3 \mathrm{~mm} \pm 0.4 \mathrm{~mm}$ ) were cut using a 6-mm-diameter biopsy punch (Steifel, Maidenhead, United Kingdom), removed from the joint, and cultured for $48 \mathrm{~h}$ in culture media at $37^{\circ} \mathrm{C}$ in a humidified atmosphere of $5 \%$ $\mathrm{CO}_{2}-95 \%$ air to establish baseline conditions. After this pretreatment period, the $6 \mathrm{~mm}$ cartilage discs were preincubated for $3 \mathrm{~h}$ in media containing inhibitors of cell death. Necrostatin1 (Nec-1; $30 \mu \mathrm{M}$; Biomol, Exeter, United Kingdom) was chosen as an inhibitor of necroptosis a necrosis-like cell death pathway. This mechanism of cell death is triggered by the same stimuli that activates apoptosis and is programmed to occur as a backup mechanism to eliminate damaged cells when apoptosis cannot occur. ${ }^{17}$ ZVF $(20 \mu \mathrm{M})$ was chosen as a cell permeable, irreversible pan-caspase inhibitor. Additional studies used Z-IETD-FMK (ZIF; $30 \mu \mathrm{M})$ as a cell permeable, irreversible caspase- 8 inhibitor ${ }^{18}$ and Z-LEHD-FMK (ZLF; $\left.30 \mu \mathrm{M}\right)$ as a cell permeable, irreversible caspase- 9 inhibitor. ${ }^{19}$ Control discs were incubated in media containing $0.2 \%$ (vol/vol) DMSO, the solvent used to solubilize the inhibitors. At the end of this period, a $3 \mathrm{~mm}$ inner disc was cut using a biopsy punch (Steifel) and left in situ, thus providing an in vitro model to study the effect of wound-induced cell death on cartilage-cartilage integration (Fig. 1). Cartilage disc/ring composites were cultured for 3 days (gene expression analysis) or 2-6 weeks (cell death/ matrix analysis and mechanical testing) in media containing the inhibitors $(n \geq 3)$ with cultures being fed with fresh media and inhibitors every $2-3$ days unless stated otherwise. DMSO $(0.2 \%)$ was added to cultures not receiving cell death inhibitors. Disc/ring composites $(+/-$ inhibitors) were compared to $6 \mathrm{~mm}$ cartilage discs.

\section{Analysis of cell death}

Determination of necrotic cell death. Primary and secondary necrotic cell death was assessed using the CytoTox

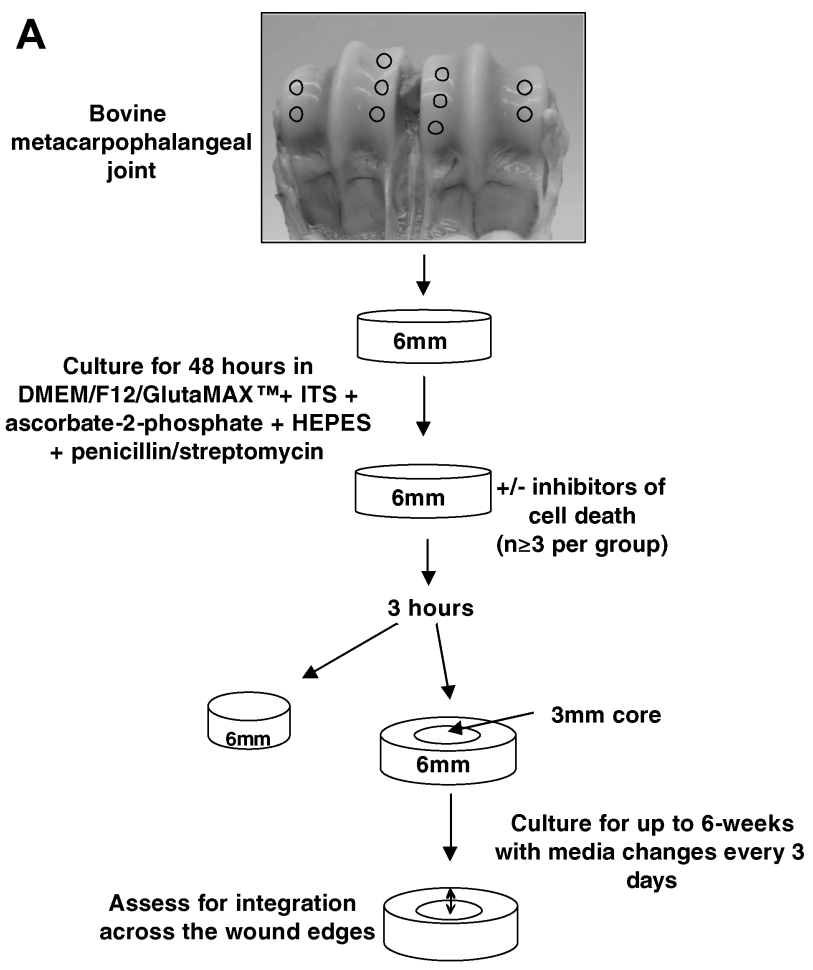

B

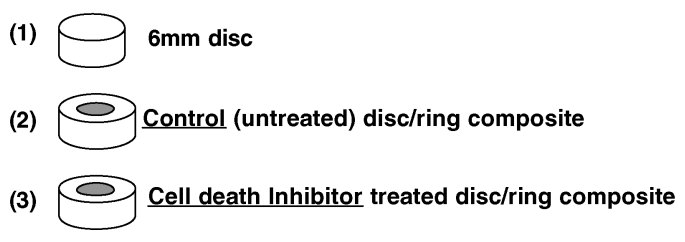

FIG. 1. Disc/ring model to study cartilage-cartilage integration. (A) Full-depth articular cartilage discs $(6 \mathrm{~mm})$ were taken from the metacarpophalangeal joint of 7-day-old bovine calves, washed in medium, and cultured for $48 \mathrm{~h}$ at $37^{\circ} \mathrm{C}$. After $48 \mathrm{~h}$, discs were incubated for $3 \mathrm{~h}$ in media with and without $(+/-)$ inhibitors of cell death. At the end of this period, a $3 \mathrm{~mm}$ inner disc was cut and left in situ, thereby creating disc/ring composites to study cartilage-cartilage integration. Composites were cultured for up to 6 weeks in media $+/-$ inhibitors ( $n \geq 3$ per treatment) with cultures being fed with fresh inhibitors every $2-3$ days. (B) Description of treatment groups used in the study.

$96^{\circledR}$ assay according to manufacturer's instructions (Promega, Southampton, United Kingdom). This assay quantitatively measures lactate dehydrogenase (LDH) present in the culture media that has been released upon natural lysis of cells during the culture period. ${ }^{20}$ Differences in the release of $\mathrm{LDH}$ associated with culture treatment were expressed as absorbance units.

Determination of apoptotic cell death. To assess the extent of apoptotic cell death, cartilage was removed from the medium, washed in phosphate-buffered saline (PBS), and fixed in $70 \%$ (vol/vol) ethanol for $12 \mathrm{~h}$ at $4 \mathrm{C}$. Disc/ring composites were processed by wax embedding and cut into $8 \mu \mathrm{m}$ sections. Sections were de-waxed, rehydrated, and analyzed using the fluorescent version of the FragEL ${ }^{\mathrm{TM}}$ DNA Fragmentation Detection Kit according to manufacturer's in- 
structions (Calbiochem, Nottingham, United Kingdom). This assay is a nonisotopic system for fluorescein labeling of DNA breaks in apoptotic nuclei. The total cell population can be visualized using a DAPI filter, thus allowing the percentage of apoptotic cells to be calculated. Detection and analysis of labeling was by fluorescence microscopy (Olympus).

\section{Analysis of proteoglycan release}

The total amount of sulfated glycosaminoglycan (sGAG) released into the culture medium over 2 weeks was measured using a modification of the 1,9-dimethylmethylene blue dye binding (DMMB) assay using chondroitin-4-sulfate-C from shark cartilage as a standard. ${ }^{21}$ Differences in the release of sGAG associated with culture treatment were expressed as $\mu \mathrm{g}$ of $\mathrm{GAG}$ per $\mathrm{mL}$ of media.

\section{Histological and immunohistological analysis of cartilage composites}

Sections (see the section Determination of apoptotic cell death) were de-waxed, rehydrated, and stained with a $0.1 \%$ aqueous solution of toluidine blue to show the distribution of glycosaminoglycans in the cartilage. Sections (two per zone for each treatment) were chosen randomly from within the superficial, mid, and deep zone and scored for the amount of integration. This was assessed under high magnification, as new tissue growth between the two cut surfaces, and expressed as a percentage of the total cut surface. Cartilagecartilage integration was also assessed by immunohistochemistry. Briefly, sections were de-waxed, rehydrated, and washed extensively in PBS before blocking in $2 \%$ (vol/vol) normal goat serum for $1 \mathrm{~h}$ at room temperature. Sections were incubated overnight at $4{ }^{\circ} \mathrm{C}$ with a mouse monoclonal antibody to type II collagen (CIICI, Hybridoma bank, NIH) diluted in PBS (1:5). Sections were subsequently washed in PBS before being incubated for $1 \mathrm{~h}$ at room temperature with a FITC-conjugated anti-mouse secondary antibody diluted 1:100 in PBS. After extensive washing in PBS, sections were mounted in Vectashield ${ }^{\circledR}$ Mounting Medium containing DAPI $(1.5 \mu \mathrm{g} / \mathrm{mL})$ to counterstain DNA (Vector Labs, Peterborough, United Kingdom). Labeling was observed using an Olympus BX61 fluorescence microscope.

\section{Scanning and transmission electron microscopy}

For scanning electron microscopy (SEM), cartilage was removed from the medium, washed in PBS, fixed in $2.5 \%$ glutaraldehyde for $3 \mathrm{~h}$ at $4^{\circ} \mathrm{C}$, and postfixed in $2 \%$ osmium tetroxide secondary fixative for $2 \mathrm{~h}$ at room temperature. The samples were fully dehydrated using $70-100 \%$ graded ethanol, critically point dried, and sputter coated under vacuum in gold. Samples were examined using the Phillips XL20 scanning electron microscope. For transmission electron microscopy (TEM), cartilage was processed postfixing for ultrastructural analysis ${ }^{22}$ and examined using the Philips 208 TEM at $80 \mathrm{kV}$.

\section{Quantitative PCR analysis of gene expression}

Cartilage explants were cultured for 3 days and snap frozen in liquid nitrogen before the addition of $1 \mathrm{~mL}$ of Trizol $^{\circledR}$ (Invitrogen). Cartilage was powdered in a dismembrator
(B. Braun Biotech, Allentown, PA), and total RNA extracted according to the manufacturer's instructions (Invitrogen) but with the following exceptions. After the addition of the chloroform, the whole RNA extraction mix was transferred to a tube containing Heavy Phase-lock Gel ${ }^{\mathrm{TM}}$ (Eppendorf $^{\circledR}$, Fisher Scientific, Loughborough, United Kingdom) and centrifuged at $13,000 \mathrm{~g}$ for $2 \mathrm{~min}$ at $4^{\circ} \mathrm{C}$. The upper aqueous layer was removed to a new Eppendorf ${ }^{\circledR}$ tube, an equal volume of isopropanol added, and the RNA left to precipitate overnight at $-20^{\circ} \mathrm{C}$. At the end of the extraction protocol, the RNA was DNase treated to remove genomic DNA (Ambion, Huntingdon, United Kingdom) and resuspended in $50 \mu \mathrm{L}$ RNasefree water. cDNA was generated in a single $20 \mu \mathrm{L}$ reaction from $11 \mu \mathrm{L}$ RNA sample using $250 \mathrm{ng}$ random hexamers $(0.5 \mathrm{mg} / \mathrm{mL}$; Promega) and Superscript III reverse transcriptase (200 units; Invitrogen).

Expression of type II collagen was measured by SYBR green quantitative PCR (qPCR) using the MX3000P ${ }^{\mathrm{TM}}$ qPCR system according to manufacturer's instructions (Stratagene ${ }^{\circledR}$ ) with $200 \mathrm{nM}$ forward (5'-AACGGTGGCTTCCACTTC-3') and reverse $\left(5^{\prime}\right.$-GCAGGAAGGTCATCTGGA-3') primers. $^{23}$ Fold change relative to $6 \mathrm{~mm}$ discs were calculated using the $\Delta \Delta \mathrm{C}_{\mathrm{T}}$ method with $18 \mathrm{~s}$ ribosomal RNA (5'-GCAATTATTCCC CATGAACG-3' and 5'-GGCCTCACTAAACCATCCAA-3') as the reference gene. ${ }^{24}$ All primers were purchased from Eurofins MWG Operon (London, United Kingdom).

\section{Western blotting}

Disc/ring cartilage composites were snap frozen in liquid nitrogen before being powdered in a dismembrator (B. Braun Biotech Int.). Proteoglycans were extracted with $4 \mathrm{M}$ guanidine- $\mathrm{HCl}$ for $24 \mathrm{~h}$ at $4^{\circ} \mathrm{C}$, and samples centrifuged at $30,000 \mathrm{~g}$ for $15 \mathrm{~min}$ at $4^{\circ} \mathrm{C}$. Pellets were washed with $0.5 \mathrm{M}$ acetic acid before digestion with pepsin (1:10 wet weight) in $0.5 \mathrm{M}$ acetic acid for $24 \mathrm{~h}$ at $4{ }^{\circ} \mathrm{C}$. Samples were centrifuged at $30,000 \mathrm{~g}$ for $15 \mathrm{~min}$ at $4^{\circ} \mathrm{C}$, and the supernatant containing pepsin-soluble collagen was analyzed by hydroxyproline assay $^{25}$ before Western blot analysis.

An equal amount of collagen from control (untreated) and ZVF-treated samples were diluted 1:1 in sample buffer $(0.12 \mathrm{M}$ Tris/ $\mathrm{HCl}[\mathrm{pH} 6.8]$, containing $4 \%$ [w/v] SDS, 20\% [v/v] glycerol, and $0.01 \%[\mathrm{w} / \mathrm{v}]$ bromophenol blue), reduced $(2.5 \%$ $\mathrm{vol} / \mathrm{vol} \beta$-mercaptoethanol), and resolved on $7.5 \%(\mathrm{wt} / \mathrm{vol})$ SDS-polyacrylamide gels. For each analysis, control and ZVFtreated samples were run on the same gel for direct comparison. Protein was transferred to PVDF membranes (Immobilon; Millipore, Watford, United Kingdom) and blocked for $1 \mathrm{~h}$ at room temperature in blocking buffer (Tris buffered saline with Tween 20 [TBST]; 0.15 M NaCl, 0.05 M Tris/ $\mathrm{HCl} \mathrm{pH} 8.0,3 \%$ [wt/vol] skimmed milk powder, and $0.05 \%$ [vol/vol] Tween 20). After washing (TBST), membranes were incubated for $2 \mathrm{~h}$ at room temperature with a monoclonal antibody to type II collagen (1:5 dilution of antibody AVT6E3 ${ }^{16}$ ) diluted in TBST. Membranes were washed and incubated for $1 \mathrm{~h}$ at room temperature in appropriate horseradish peroxidase-conjugated IgG. Bands were detected using enhanced chemiluminescence reagents using multiple sheets of Hyperfilm-ECL (GE Healthcare, Little Chalfont, United Kingdom), and various exposure times to ensure samples were within the linear range. ${ }^{26}$ Blots were scanned (Umax Magic scan) and analyzed by densitometry (NIH Image). 


\section{Mechanical testing}

Disc/ring composites were treated with ZVF for 4-days and cultured for a total of 6 weeks. Adhesive properties of the disc/ring interface after 6 weeks in culture were assessed using a push-out test. Thickness of the sample was measured using calipers. A custom-made mechanical testing device in which a push-out rod displaced the disc from the ring (at a rate of $1 \times 10^{-18} \mathrm{~N} / \mathrm{mm}^{2} / \mathrm{s}$ ) was used to test the adhesive strength with a Lloyd LRX material testing machine (Lloyds Instruments, Hants, UK). A computer-activated micro-stepper controlled the displacement of the push-out rod, while a load cell $(100 \mathrm{~N})$ coupled to the rod measured the push-out force. The adhesive strength was calculated from the maximum force measured at failure per unit of interfacial area.

\section{Statistical analysis}

Where appropriate, data are presented as mean \pm SEM ( $n \geq 3$ replicates per treatment) and tested for normality and equal variances before parametric analysis (Minitab).

\section{Results}

\section{Effect of Nec-1 and ZVF on chondrocyte death}

Analysis of necrotic cell death. Significant differences were observed in the extent of $\mathrm{LDH}$ release into the media during the first $48 \mathrm{~h}$ of culture representing primary and secondary necrosis (one-way ANOVA, $p<0.001$; Fig. 2A). Establishing the disc/ring composites resulted in a significant increase in LDH release (Fisher's post hoc test; $p<0.001$ ). Treatment of disc/ring composites with ZVF significantly reduced the extent of necrosis that occurred within $48 \mathrm{~h}$ of wounding (Fisher's post hoc test; $p<0.001$ ) so that necrosis levels were not significantly different to levels in the $6 \mathrm{~mm}$ discs. Nec-1 reduced LDH release when compared to control (untreated) disc/ring composites (Fisher's post hoc test; $p<0.01$ ), but levels were still significantly higher than the $6 \mathrm{~mm}$ discs (Fisher's post hoc test; $p<0.01$ ). Similar trends were observed over the first 7 days in culture after which negligible $\mathrm{LDH}$ release occurred in all cultures (data not shown).

Analysis of apoptotic cell death. The effect of wounding on apoptosis and the efficacy of the pan-caspase inhibitor, ZVF, in inhibiting apoptosis was assessed using the FragEL $^{\text {TM }}$ DNA Fragmentation Detection Kit (Calbiochem). After 2 weeks of culture, disc/ring composites were sectioned and analyzed for the presence of apoptotic nuclei (Fig. 2B). In the superficial zone of control (untreated) disc/ring composites, extensive numbers of apoptotic nuclei were detected extending several micrometers from the wound edge of both the inner disc and outer ring. In the mid zone, apoptotic nuclei were present but were more restricted to the wound edge. Treatment with ZVF markedly reduced the number of apoptotic nuclei detected in the superficial and mid zones. Equivalent numbers of apoptotic nuclei were detected in the deep zone of control and ZVF-treated composites (sections not shown).

\section{Effect of Nec-1 and ZVF on the release of proteoglycans}

Using the DMMB assay, significant differences were observed in the total amount of sGAG released into the media over 2 weeks (one-way ANOVA, $p<0.05$; Fig. 2C). The level of sGAG released into the media was higher in disc/ring cultures compared to the $6 \mathrm{~mm}$ discs (Fisher's post hoc test; $p<0.05)$. Treatment of disc/ring composites with either of the inhibitors resulted in levels of sGAG in the media that were comparable to the $6 \mathrm{~mm}$ discs.

\section{Effect of Nec-1 and ZVF \\ on cartilage-cartilage integration}

Disc/ring composites were cultured for 2 weeks in the presence or absence of cell death inhibitors, fixed, embedded in wax, and $8 \mu \mathrm{m}$ sections assessed for integration by immunolabeling for type II collagen (Fig. 3A). Disc/ring composites that had not been treated with cell death inhibitors consistently showed no signs of integration, whereas enhanced integration was observed in cartilage composites treated with ZVF or Nec-1. The extent of integration was further analyzed by staining sections with toluidine blue for the presence of proteoglycans (Fig. 3B, C). Little or no integration of wound edges was observed throughout the full depth of control (untreated) disc/ring composites (1.0-5.5\% of the total wound edge). In contrast, treatment with ZVF resulted in enhanced integration around the entire cut surface, throughout the full depth of the tissue $(61.0-71.0 \%$ of the total wound edge). When ZVF-treated composites were analyzed under higher power (Fig. 3C), areas of complete integration were seen as well as areas of newly forming tissue. Nec-1 treatment improved integration compared to control disc/ring composites but not around the entire cut surface and not throughout the full depth $(7.0-34.5 \%$ of the total wound edge). Because the use of ZVF to inhibit cell death produced more complete areas of integration and reduced LDH and sGAG release, apoptotic death pathways were targeted for further investigation.

\section{Targeting of specific caspases}

To determine whether specific caspases could be targeted to improve integration, disc/ring composites cultured in the presence of the pan-caspase inhibitor, ZVF, were compared to those treated with the caspase- 8 inhibitor, ZIF, or the caspase9 inhibitor, ZLF. SEM was used to assess the extent of integration at the end of 2 weeks in culture (Fig. 4A). Control composites showed no signs of integration, whereas almost complete integration of the wound edges was observed in composites treated with the pan-caspase inhibitor, ZVF. Dis$c /$ ring composites treated with either ZIF or ZLF showed some areas of integration but not to the same extent as ZVF.

To establish whether integration was occurring throughout the full depth of the cartilage, sections were taken from the superficial, mid, and deep zones and stained with toluidine blue for the presence of proteoglycans (Fig. 4B). In the superficial zone of control composites, there were some areas where new proteoglycan was forming but also extensive areas of little or no new tissue formation. There were no areas of complete integration. Within the mid zone there were areas of no tissue formation as well as areas where complete wound closure had occurred. Treatment with the caspase-9 inhibitor, ZLF, improved integration in the superficial zone and resulted in areas of complete wound closure, partial infilling of the wound gap, as well as areas of 
A

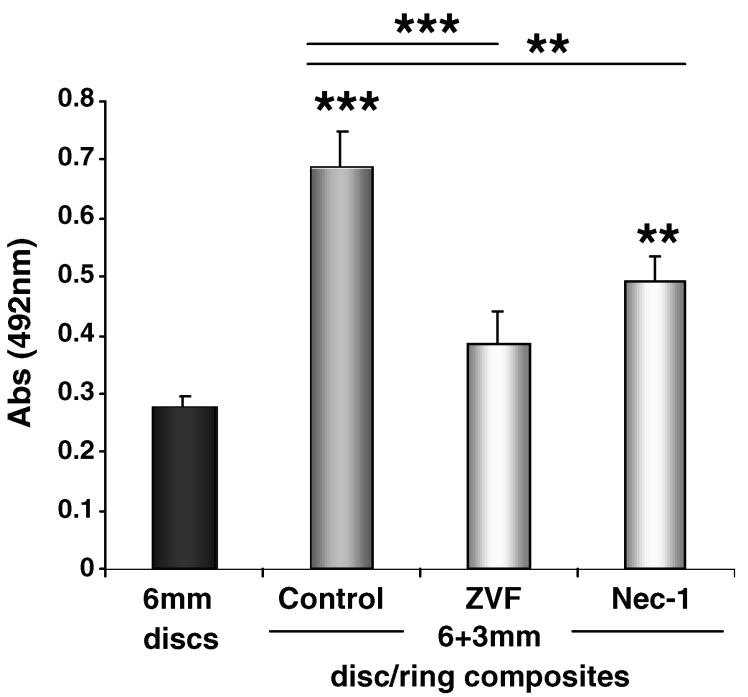

B
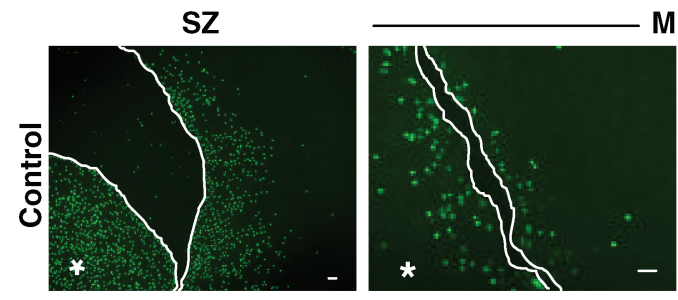

Mid
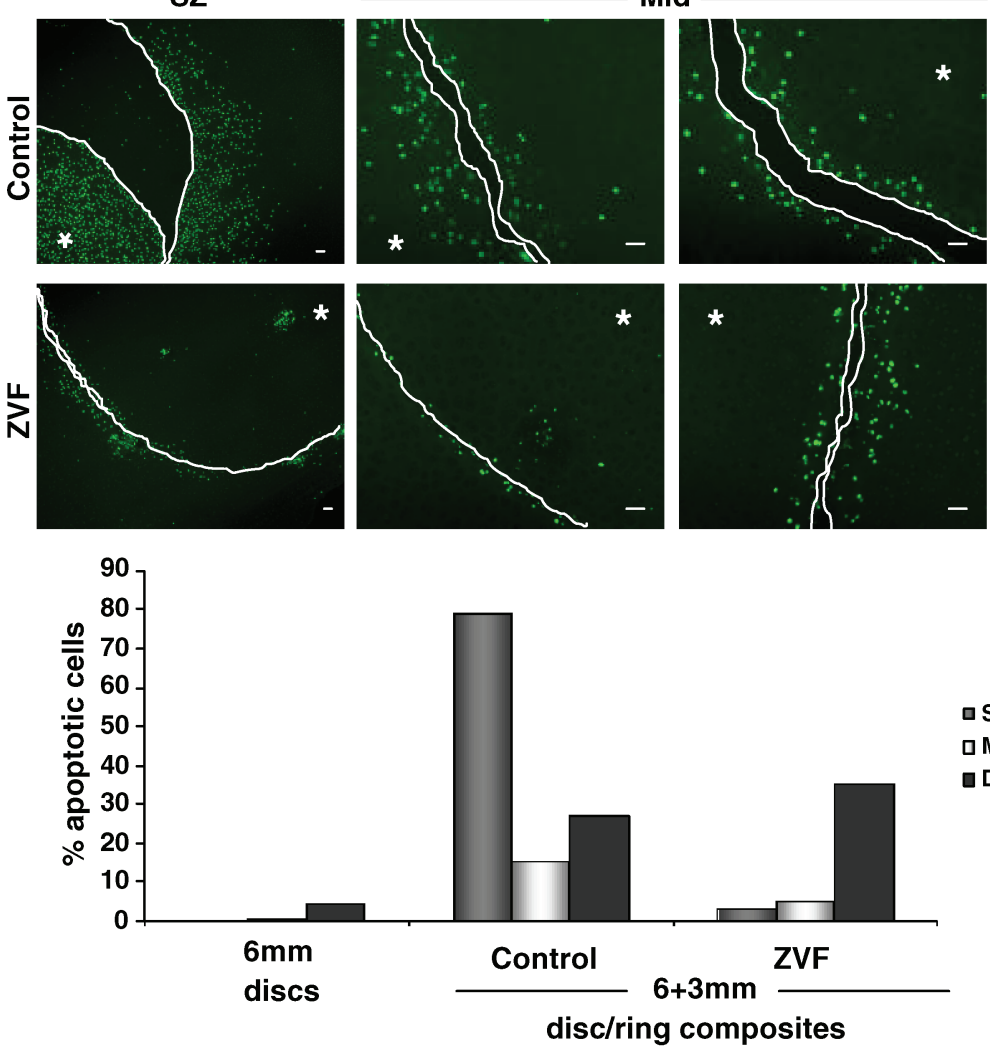

C

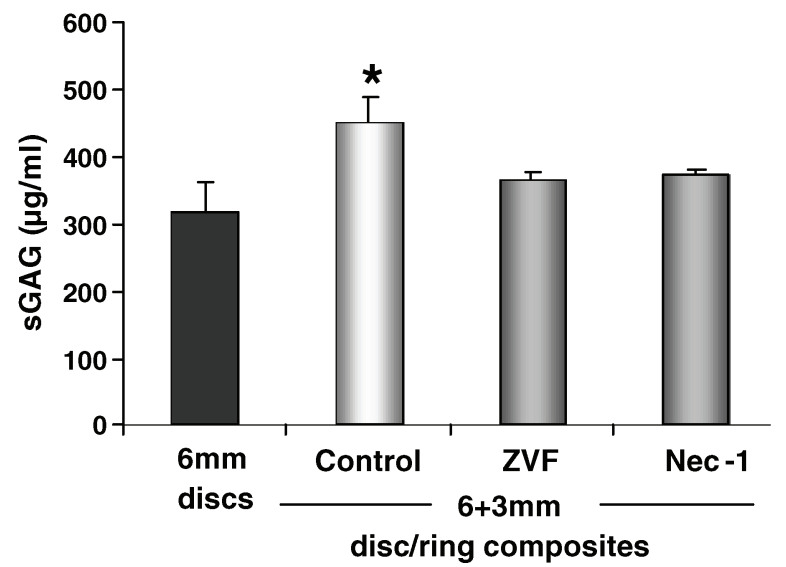

FIG. 2. Analysis of cell death and sGAG loss. (A) Primary and secondary necrotic cell death occurring in cartilage composites treated with various cell death inhibitors in the $48 \mathrm{~h}$ postwounding was assessed by measuring LDH release into the culture media (one-way ANOVA and Fisher's post hoc test; ${ }^{* *} p<0.01$ and ${ }^{* * *} p<0.001 ; n=3$ composites per treatment). (B) The effect of wounding on apoptosis and the efficacy of the pan-caspase inhibitor, ZVF, in inhibiting apoptosis was assessed using the FragEL ${ }^{\mathrm{TM}}$ DNA Fragmentation Detection Kit. Cartilage was cultured for 2 weeks, and sections were analyzed for the presence of apoptotic nuclei. Superficial and mid zone sections are shown. Wound edges (white lines) and inner $(3 \mathrm{~mm})$ disc $(*)$ are indicated. The number of apoptotic nuclei in the superficial (SZ), mid, and deep zones were counted, plotted graphically as a percentage of the total number of cells, and compared to $6 \mathrm{~mm}$ discs. Scale

bars $=100 \mu \mathrm{m}$. (C) The amount of sGAG lost into the media over the 2-week culture period was assessed using the

DMMB assay. Cartilage composites were cultured in the presence or absence of cell death inhibitors for 2 weeks, and media collected every 2-3 days. Data are plotted as total $\mathrm{sGAG} \pm \mathrm{SEM}(\mu \mathrm{g} / \mathrm{mL})$ and analyzed by one-way ANOVA and Fisher's post hoc test ${ }^{*} p<0.05 ; n=3$ per treatment). Color images available online at www.liebertonline.com/ten. 
A

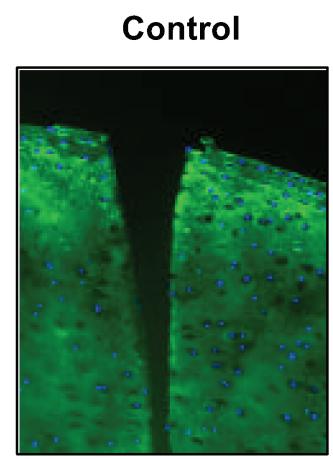

B

FIG. 3. Histological and immunohistological analysis of cartilage-cartilage integration.

Disc/ring composites were cultured for 2 weeks in the presence or absence of cell death inhibitors, fixed, embedded in wax, and $8 \mu \mathrm{m}$ sections assessed for integration by immunohistochemistry (A) and histology $(B, C)$. (A) Sections were stained for the presence of type II collagen using a monoclonal antibody to the triple helical region of the molecule (CIICI) followed by FITC-conjugated secondary. Sections were mounted in Vectashield containing DAPI to counterstain DNA. Arrows indicate areas of integrative repair. Scale bar $=100 \mu \mathrm{m}$. (B) Sections were stained with toluidine blue to detect proteoglycans. Sections shown are representative of two sections chosen randomly from the superficial (SZ), mid, and deep zones. The amount of integration, assessed under high magnification as new tissue growth between the two cut surfaces, is shown below each panel expressed as a percentage of the total cut surface. Scale bar $=1 \mathrm{~mm}$. (C) Detailed view of the interface region from ZVFtreated and Nec-1-treated cartilage. Arrows indicate wound edge. Scale bar $=100 \mu \mathrm{m}$. Color images available online at www.liebertonline.com/ten.

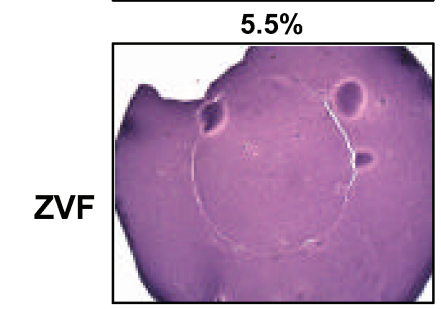

$71.0 \%$

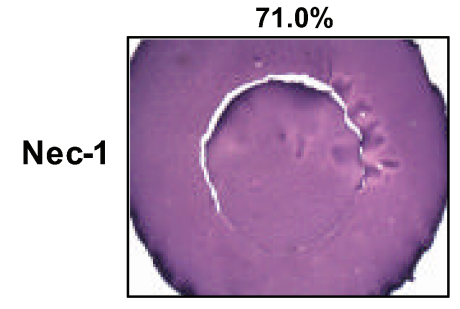

$34.5 \%$

C
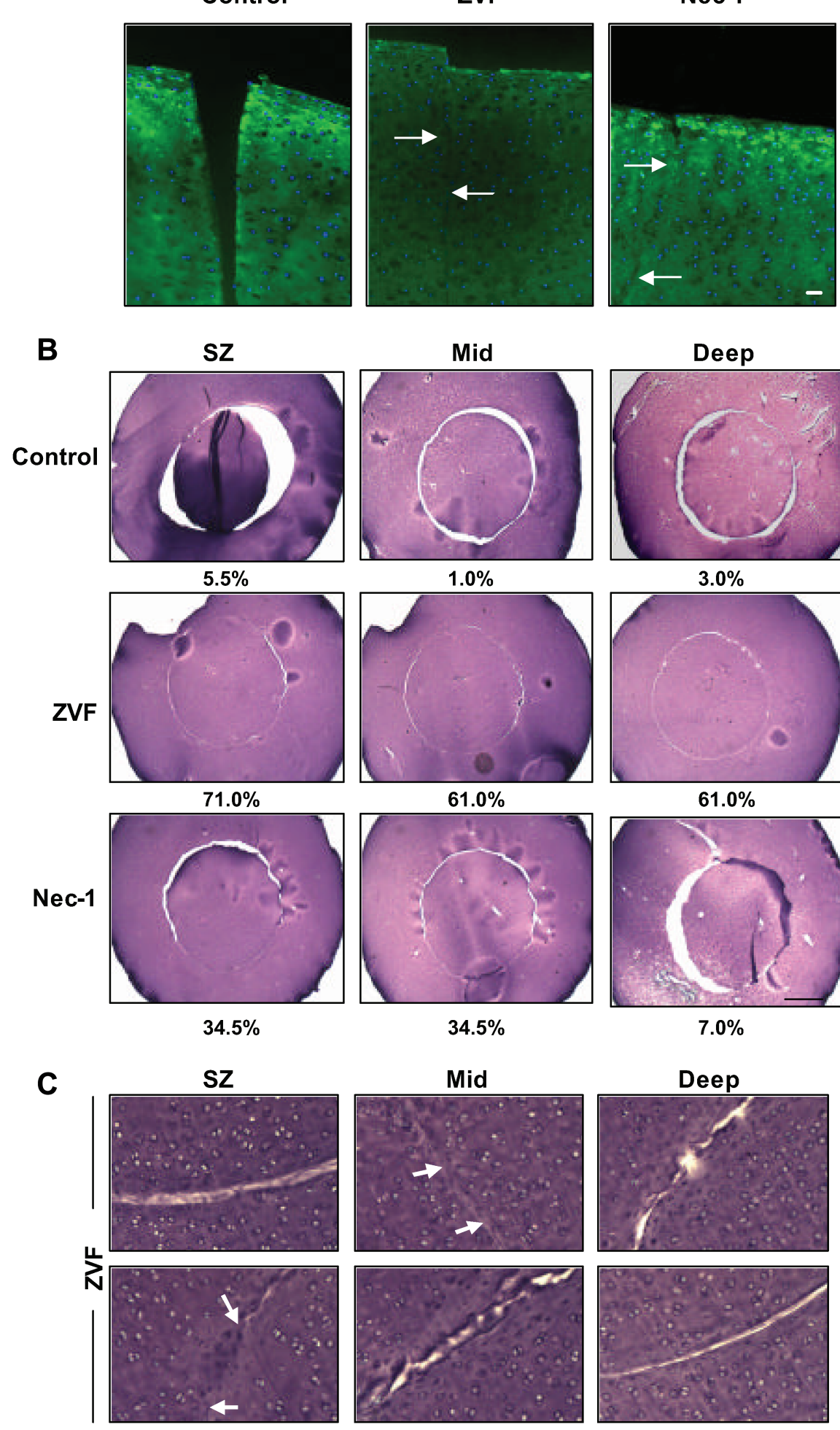

$61.0 \%$

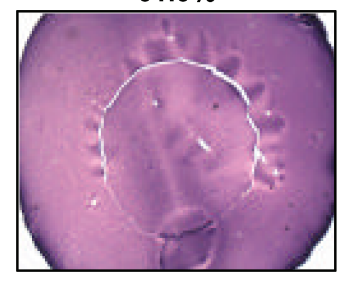

$34.5 \%$

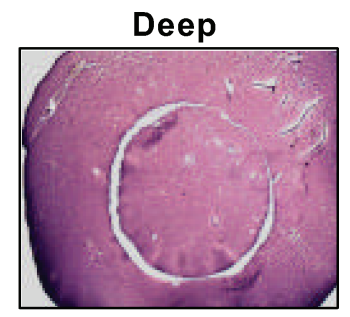

$3.0 \%$

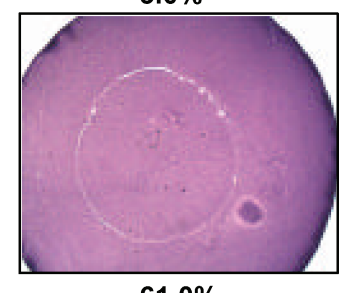

$61.0 \%$

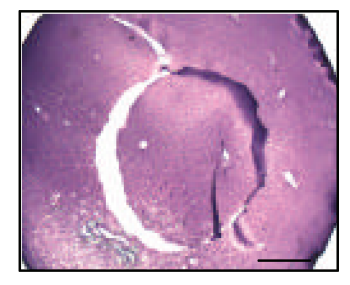

$7.0 \%$
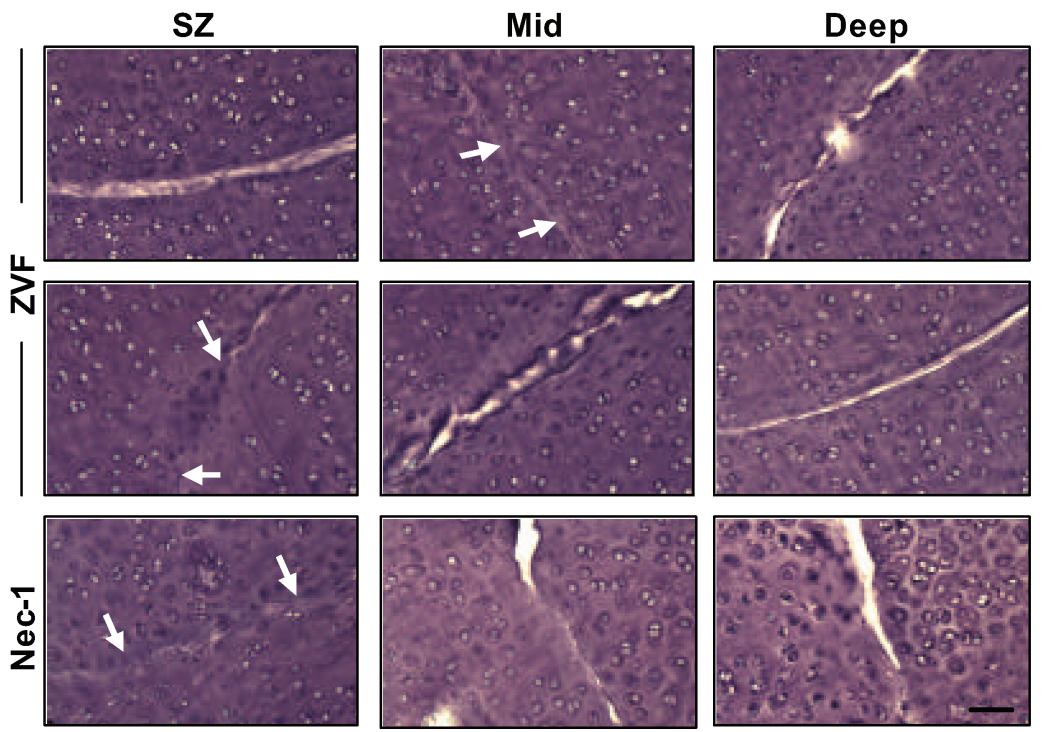
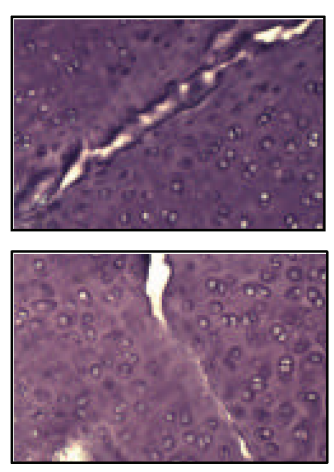

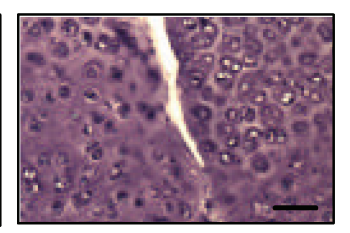


A
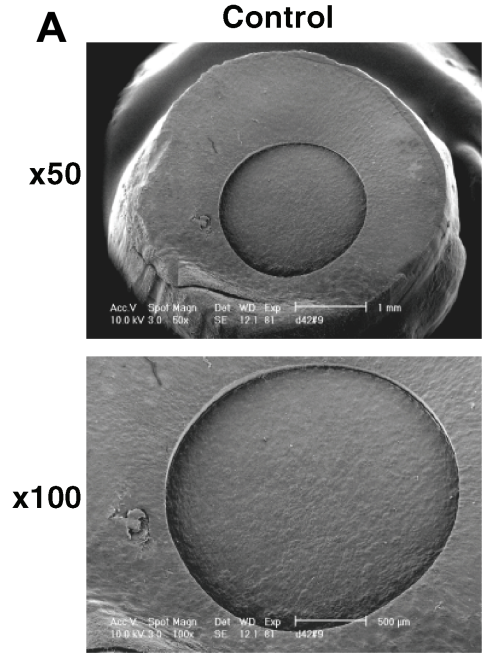

ZVF
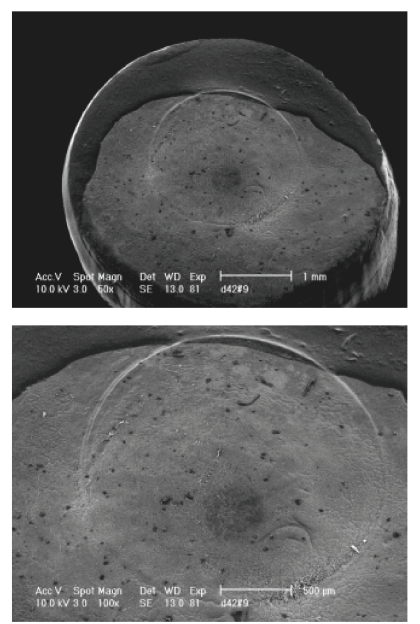

ZIF
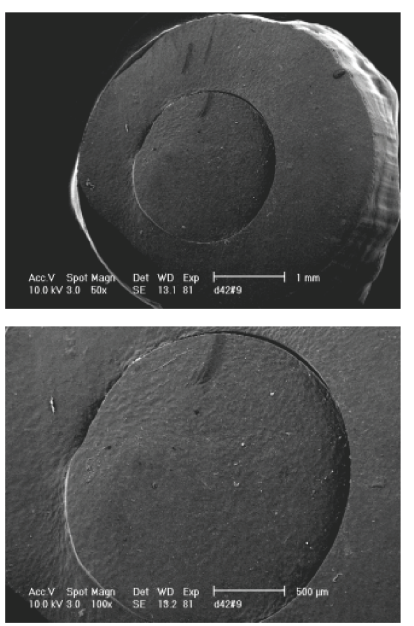

ZLF
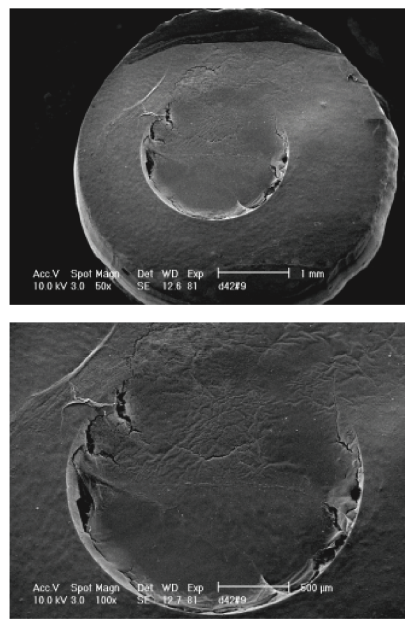

B
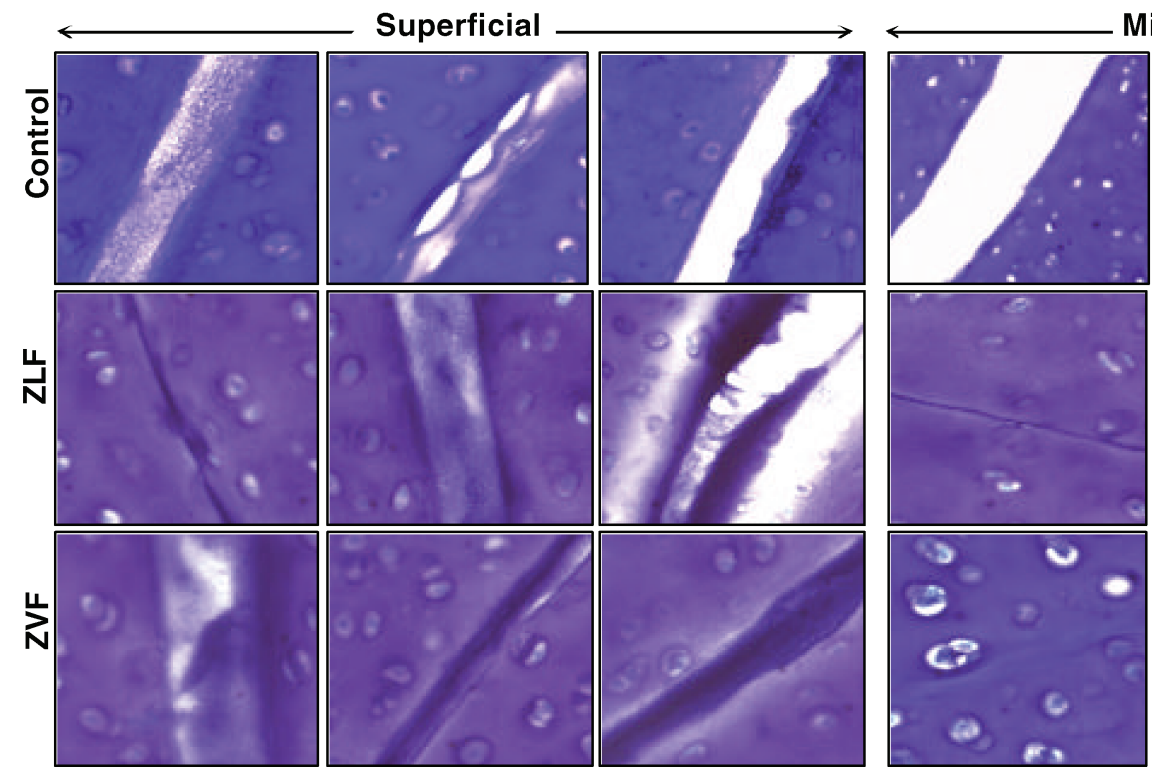

Mid

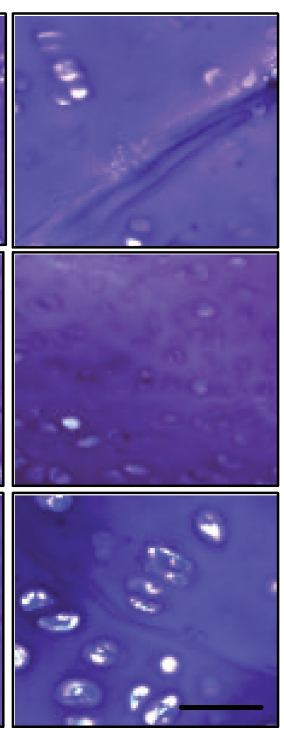

FIG. 4. Analysis of integration after targeted caspase inhibition. To determine whether specific caspases could be targeted to improve integration, disc/ring composites were cultured in the presence of the pan-caspase inhibitor, ZVF, the caspase-8 inhibitor, ZIF, or the caspase-9 inhibitor, ZLF. At the end of 2 weeks, cartilage was (A) processed and examined using SEM (top panels, $\times 50$ magnification; bottom panels, $\times 100$ magnification) or (B) fixed, embedded in wax, and $8 \mu \mathrm{m}$ sections stained with toluidine blue to detect proteoglycans. Sections taken from the superficial and mid zones of cartilage left untreated (top panels), treated with ZLF (mid panels), and treated with ZVF (bottom panels) are shown. Scale bar $=100 \mu \mathrm{m}$. Color images available online at www.liebertonline.com/ten.

little integration. Within the mid zone, there were areas of wound closure and complete tissue integration. Results were similar in composites treated with the caspase-8 inhibitor, ZIF (data not shown). In disc/ring composites treated with the pan-caspase inhibitor, ZVF, integration was observed within the superficial zone, and there were fewer areas of partial proteoglycan infilling and more areas where complete wound closure was apparent. Integration was observed between large areas of the wound edge within the mid zone.

\section{Analysis of extracellular matrix expression and deposition}

Quantitative PCR was performed to determine whether inhibiting wound-induced apoptosis with ZVF altered type
II collagen mRNA expression (Fig. 5A). Within 3 days of treatment with $\mathrm{ZVF}$, disc/ring composites exhibited a significant, 9.6-fold increase in the expression of type II collagen mRNA compared to control (untreated) disc/ring composites (Student's two-sample $t$-test, $p<0.001$; Fig. 5A) and a 5.6fold increase over the $6 \mathrm{~mm}$ discs (Student's two-sample $t$-test, $p<0.05 ;$ Fig. 5A).

In addition, after 3 weeks in culture, pepsin-soluble collagen was extracted from control and ZVF-treated disc/ring composites, and an equivalent amount of total collagen analyzed for type II collagen quantification by Western blotting (Fig. 5B). After 3 weeks, there was no significant difference in the amount of type II collagen protein present in the total disc/ring composite (Student's two-sample $t$-test, $p=0.100$, after Johnson's transformation of data). 
A

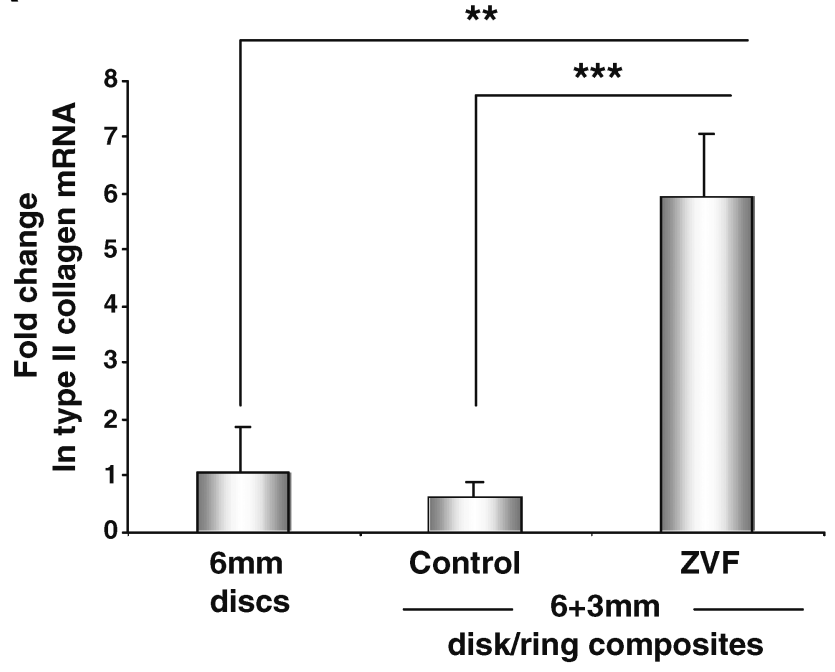

B

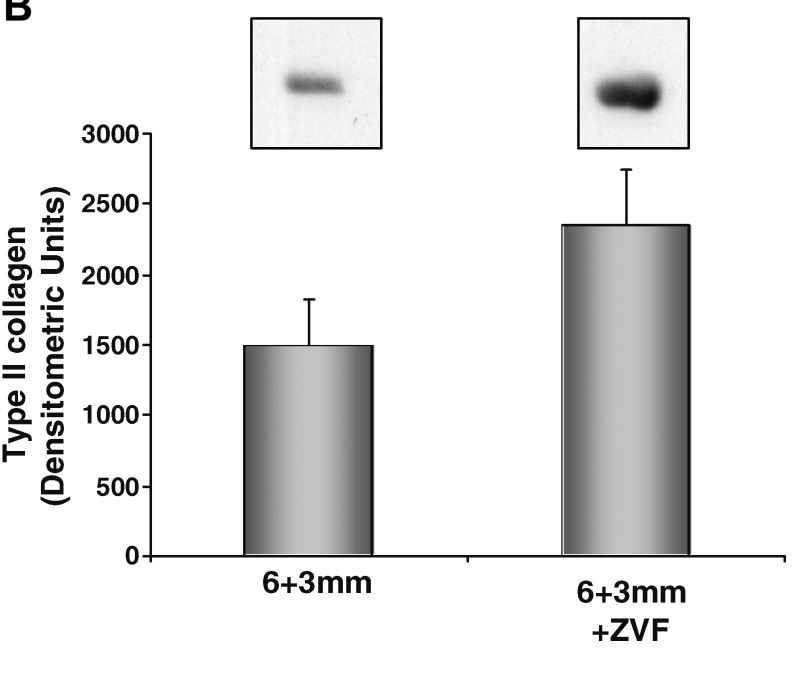

C
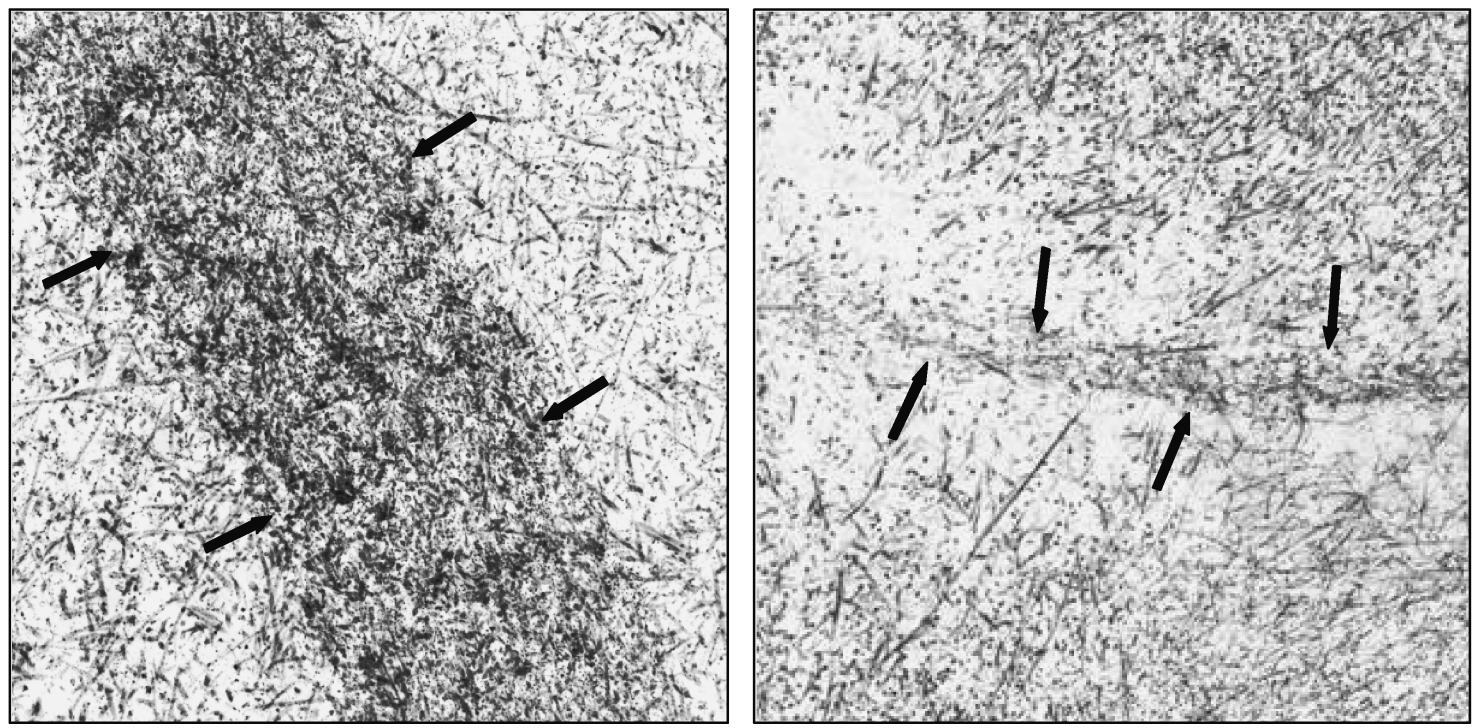

FIG. 5. Analysis of type II collagen expression and deposition. (A) RNA from $6 \mathrm{~mm}$ discs $(n=4)$, and untreated ( $n=6)$ or ZVF-treated $(n=5)$ disc/ring composites was analyzed by quantitative PCR to determine the relative expression of type II collagen. Data are presented as fold change relative to $6 \mathrm{~mm}$ discs calculated using the $\Delta \Delta \mathrm{C}_{\mathrm{T}}$ method with $18 \mathrm{~s}$ ribosomal RNA as the reference gene and plotted as mean \pm SEM (Student's two-sample $t$-test, ${ }^{* * *} p<0.001$ and ${ }^{* *} p<0.01$ ). (B) Pepsinsoluble collagen was extracted from disc/ring composites cultured for 3 weeks and an equivalent amount of total collagen analyzed for type II collagen by Western blotting. Control and ZVF-treated samples were run on the same gel to allow direct comparisons to be made. Levels of type II collagen are plotted as mean densitometric units \pm SEM ( $n=4$ per treatment; Student's two-sample $t$-test, $p=0.100)$. (C) At the end of 2 weeks in culture, cartilage composites were processed for dedicated ultra-structural analysis by TEM. Collagen fibrils were observed between the wound edges of ZVF-treated composites (magnification, $\times 8000$ ). Narrower wound gaps were observed in some areas (magnification, $\times 10,000$ ). Arrows indicate the wound edges.

TEM was used to observe the ultra-structure of the matrix forming between the wound edges of ZVF-treated disc/ring composites (Fig. 5C). After 2 weeks, a basket-like weave of newly formed collagen fibrils was observed between the wound edges of ZVF-treated cartilage. In some areas, a narrower wound gap was observed.

\section{Mechanical testing}

The adhesive strength of the interface material formed after 6 weeks in culture was tested by push-out test (Fig. 6A).
A significant difference was detected in the stress-to-failure in ZVF-treated disc/ring composites over control composites $\left(0.333 \pm 0.041 \mathrm{~N} / \mathrm{mm}^{2}\right.$ vs. $\left.0.065 \pm 0.043 \mathrm{~N} / \mathrm{mm}^{2}\right)$ (Student's two-sample $t$-test, $p=0.003$; Fig. 6B).

\section{Discussion}

This study utilized a bovine articular cartilage disc/ring composite model to assess the effects of inhibiting cell death on cartilage-integrated repair. Bovine cartilage has been widely used to investigate cartilage integration and produces 

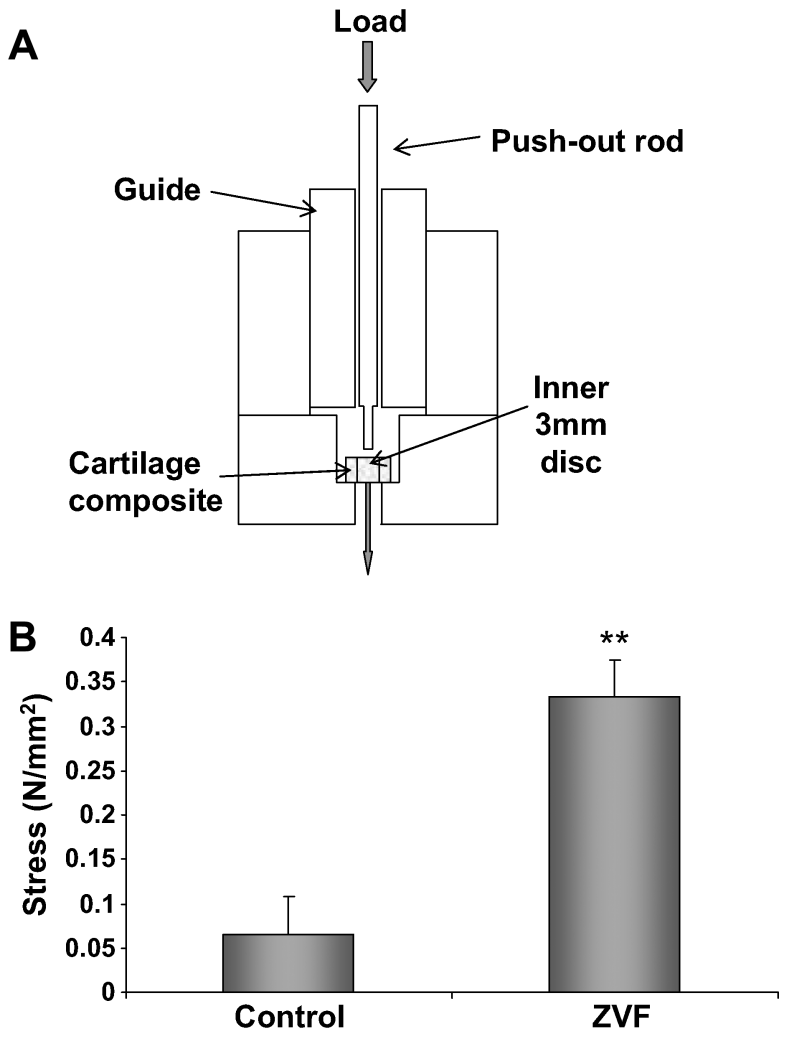

FIG. 6. Mechanical testing of newly formed tissue at the interface. (A) Schematic representation of the custom-built push-out rig. A computer-activated micro-stepper controls the displacement of the push-out $\operatorname{rod}\left(1 \times 10^{-18} \mathrm{~N} / \mathrm{mm}^{2} / \mathrm{s}\right)$, while a load cell $(100 \mathrm{~N})$ coupled to the rod measured the push-out force. (B) After 6 weeks in culture, the adhesive strength of the newly formed interface material was calculated from the maximum force measured at failure $(\mathrm{N})$ per unit of interfacial area $\left(\mathrm{mm}^{2}\right)$. Data are presented as mean \pm SEM of control $(n=4)$ and ZVF-treated $(n=5)$ disc/ring composites and analyzed by Student's two-sample $t$-test $(* * p=0.003)$.

a reproducible response upon surgical wounding indicative of early trauma in the joint, thus providing a model system to study the basic mechanisms behind cartilage repair. ${ }^{12,27,28}$ Given that increasing cell viability at the wound edge aids in the integrative process, ${ }^{9}$ we investigated whether inhibition of cell death pathways results in enhanced, integrated cartilage repair. Necrotic and apoptotic cell death pathways were chosen as targets because these have both been shown to be induced by wounding in articular cartilage. ${ }^{2}$ An increase in both necrotic and apoptotic cell death was observed after establishment of the disc/ring composites. This is in agreement with recent results showing that experimental wounding of articular cartilage leads to cell death at the lesion edge ${ }^{2-4}$ and thus confirms that our model mimics established models of cartilage wounding with respect to the cell death response. The loss of cell viability that was observed after establishment of the model was significantly reduced by preincubating the cartilage, before cutting the $3 \mathrm{~mm}$ disc, with inhibitors of cell death pathways-in particular, ZVF. The fact that ZVF, an apoptosis inhibitor, re- duced LDH release, a marker of necrosis, suggests a secondary necrotic response after an initial apoptotic stimulus. This phenomenon may occur in cartilage where in the absence of phagocytosis to remove the dead cells, membrane integrity is lost and the cell disintegrates. ${ }^{29}$ In addition to increasing cell death, wounding also increased proteoglycan loss from the cartilage composites that over the culture period could be reduced by incubating the composites with the cell death inhibitors. These data suggest that inhibiting the wound-induced death prevents matrix loss and may contribute to improved integration. In addition, the expression of mRNA for type II collagen, the matrix component most important for mechanical integrity of articular cartilage, was enhanced almost 10 -fold by inhibiting cell death. Analysis of type II protein levels showed no significant enhancement over a 3-week period although levels detected in the whole explant were $60 \%$ higher. This suggests that either with more time or by sampling only the wound edges, the protein levels may better correlate with the mRNA expression data showing significantly increased type II collagen deposition essential for an effective repair.

In all cases, inhibition of cell death improved cartilage integrative repair with the percentage of contact between wound edges (new tissue formed) being substantially more with each of the inhibitors than that observed in untreated composites. Inhibition of cell death with ZVF, however, consistently produced a more superior integration in that there was a higher percentage of contact around the whole of the wound edge in addition to better integration throughout the full depth of the cartilage. ZVF markedly reduced the number of apoptotic nuclei detected that appeared to coincide with areas of enhanced integration (see Fig. 2B). Interestingly, where there were higher levels of apoptotic nuclei, integration appeared impeded, supporting a direct relationship between the number of viable cells and successful cartilage-cartilage integration.

Because the use of an apoptotic cell death inhibitor appeared to enhance integration around the wound edge and throughout the depth of the cartilage, over that achieved with inhibition of necrotic-like death pathways, two specific caspases were targeted in an attempt to delineate the apoptosis pathway involved. The caspase- 8 inhibitor, ZIF, was chosen as an inhibitor of the death receptor-induced apoptosis pathway, and the caspase-9 inhibitor, ZLF, as an inhibitor of the mitochondrial apoptosis pathway. SEM indicated that while all three caspase inhibitors improved integration compared to that observed in untreated, control composites, the extent of integration was better in ZVFtreated cartilage $(\mathrm{ZVF}>\mathrm{ZIF}>\mathrm{ZLF})$. The observation that ZLF was less successful in enhancing integration may be due to the fact that this inhibitor induced more necrosis and sGAG loss (data not shown). This finding was supported by histology. Interestingly, toluidine blue staining indicated that while there was evidence of new GAG synthesis between the wound edges of control cartilage, total integration within the superficial zone was impeded. This was in contrast to composites treated with the caspase inhibitors that had areas of complete integration within this zone. This is in keeping with the finding that the majority of wound-induced apoptosis occurs within this zone, which is consistent with previously published data. ${ }^{2,7}$ Thus, inhibiting this death would 
maintain viable cells close to the wound edge to aid integration, again confirming the close correlation between the number of viable cells and successful integration. The relative effectiveness of the three inhibitors suggests that more than one apoptotic mechanism is activated by wounding, hence the pan-caspase inhibitor, ZVF, being by far the most efficacious in enhancing the repair process.

Ultra-structural analysis of the interfacial material to investigate the integrative repair response in more detail revealed the presence of a basket-like weave of collagen fibrils between the wound edges of ZVF-treated cartilage. The size of the wound gap was variable, with some areas being narrower than others. This observation is consistent with the findings of Moretti et al., who found variable wound gap widths but showed that more mature fibrils were present only within the narrowest of interfacial regions. ${ }^{27}$ As a functional test of the integration, push-out testing was used to determine the adhesive strength of the newly formed tissue at the wound edge. After 6 weeks in culture, ZVF significantly enhanced the adhesive strength. Overall, the adhesive strength of the newly formed material was low. The presence of more immature fibrils between the wound edges, not extensively crossing into the surrounding cartilage matrix, may provide an explanation for this. Moretti et al. also showed the presence of small immature collagen fibrils that were not integrated with the adjacent explant matrix in their disc/ring composites and hypothesized that this contributed to the relatively low adhesive strength of the composites. ${ }^{27}$ Previous studies have shown that cartilage integration is mediated by collagen deposition ${ }^{30}$ and that the deposition of collagen fibrils between the wound edges in ZVF-treated composites would support this. In addition, we hypothesize that this collagen is type II collagen because its expression is increased in disc/ring composites treated with ZVF. An extended culture period will enable the newly formed fibrils to mature by aggregating into larger, banded fibrils and undergoing crosslinking comparable to the endogenous tissue.

This study has shown, for the first time, that by using broad spectrum inhibitors of apoptotic cell death, the extent of cell death at the wound edge can be significantly reduced resulting in enhanced tissue integration in immature tissue in vitro. Further studies are, therefore, clearly warranted to study the use of caspase inhibitors in a wider setting particularly in older tissue as well as in vivo because they may be a good candidate to promote cartilage integration, a process that remains problematical in clinical cartilage repair strategies.

\section{Acknowledgments}

This project was cofunded by the Technology Strategy Board's Collaborative Research and Development program, following an open competition and Smith \& Nephew. The type II collagen antibody CIICI was obtained from the Developmental Studies Hybridoma Bank developed under the auspices of the NICHD and maintained by the Department of Biological Sciences, University of Iowa, Iowa City, IA. The authors would like to thank Dr E. Blain for critical appraisal of the manuscript and Dr A. Vaughan-Thomas for provision of the AVT6E3 antibody. Funding: Department for Business Enterprise \& Regulatory Reform, and Smith \& Nephew.

\section{Disclosure Statement}

This project was co-funded by Smith \& Nephew Ltd and the United Kingdom government through its Technology Strategy Board (TSB).

\section{References}

1. Mankin, H.J. The response of articular cartilage to mechanical injury. J Bone Joint Surg Am 64, 460, 1982.

2. Tew, S.R., Kwan, A.P., Hann, A., Thomson, B.M., and Archer, C.W. The reactions of articular cartilage to experimental wounding: role of apoptosis. Arthritis Rheum 43, 215, 2000.

3. Hembry, R.M., Dyce, J., Driesang, I., Hunziker, E.B., Fosang, A.J., Tyler, J.A., and Murphy, G. Immunolocalization of matrix metalloproteinases in partial-thickness defects in pig articular cartilage. A preliminary report. J Bone Joint Surg Am 83A, 826, 2001.

4. Hunziker, E.B., and Quinn, T.M. Surgical removal of articular cartilage leads to loss of chondrocytes from cartilage bordering the wound edge. J Bone Joint Surg Am 85A Suppl 2, 85, 2003.

5. Kim, H.T., Lo, M.Y., and Pillarisetty, R. Chondrocyte apoptosis following intraarticular fracture in humans. Osteoarthritis Cartilage 10, 747, 2002.

6. Costouros, J.G., Dang, A.C., and Kim, H.T. Inhibition of chondrocyte apoptosis in vivo following acute osteochondral injury. Osteoarthritis Cartilage 11, 756, 2003.

7. Costouros, J.G., Dang, A.C., and Kim, H.T. Comparison of chondrocyte apoptosis in vivo and in vitro following acute osteochondral injury. J Orthop Res 22, 678, 2004.

8. Huntley, J.S., McBirnie, J.M., Simpson, A.H., and Hall, A.C. Cutting-edge design to improve cell viability in osteochondral grafts. Osteoarthritis Cartilage 13, 665, 2005.

9. Janssen, L.M., In der Maur, C.D., Bos, P.K., Hardillo, J.A., and van Osch, G.J. Short-duration enzymatic treatment promotes integration of a cartilage graft in a defect. Ann Otol Rhinol Laryngol 115, 461, 2006.

10. Calandruccio, R., and Gilmer, W.J. Proliferation, regeneration, and repair of articular cartilage of immature animals. J Bone Joint Surg Am 44, 431, 1962.

11. Reindel, E.S., Ayroso, A.M., Chen, A.C., Chun, D.M., Schinagl, R.M., and Sah, R.L. Integrative repair of articular cartilage in vitro: adhesive strength of the interface region. J Orthop Res 13, 751, 1995.

12. van de Breevaart Bravenboer, J., In der Maur, C.D., Bos, P.K., Feenstra, L., Verhaar, J.A., Weinans, H., and van Osch, G.J. Improved cartilage integration and interfacial strength after enzymatic treatment in a cartilage transplantation model. Arthritis Res Ther 6, R469, 2004.

13. Bos, P.K., DeGroot, J., Budde, M., Verhaar, J.A., and van Osch, G.J. Specific enzymatic treatment of bovine and human articular cartilage: implications for integrative cartilage repair. Arthritis Rheum 46, 976, 2002.

14. Dang, A.C., Warren, A.P., and Kim, H.T. Beneficial effects of intra-articular caspase inhibition therapy following osteochondral injury. Osteoarthritis Cartilage 14, 526, 2006.

15. Costouros, J.G., and Kim, H.T. Preventing chondrocyte programmed cell death caused by iatrogenic injury. Knee 14, 107, 2007.

16. Gilbert, S.J., Blain, E.J., Jones, P., Duance, V.C., and Mason, D. Exogenous sphingomyelinase increases collagen and sulphated glycosaminoglycan production by primary articular chondrocytes: an in vitro study. Arthritis Res Ther 8, R89, 2006.

17. Degterev, A., Huang, Z., Boyce, M., Li, Y., Jagtap, P., Mizushima, N., Cuny, G.D., Mitchison, T.J., Moskowitz, M.A., and Yuan, J. Chemical inhibitor of nonapoptotic cell death 
with therapeutic potential for ischemic brain injury. Nat Chem Biol 1, 112, 2005.

18. Fadeel, B., Hassan, Z., Hellstrom-Lindberg, E., Henter, J.I., Orrenius, S., and Zhivotovsky, B. Cleavage of Bcl-2 is an early event in chemotherapy-induced apoptosis of human myeloid leukemia cells. Leukemia 13, 719, 1999.

19. Martin, D.A., Siegel, R.M., Zheng, L., and Lenardo, M.J. Membrane oligomerization and cleavage activates the caspase-8 (FLICE/MACHalpha1) death signal. J Biol Chem 273, 4345, 1998.

20. Gilbert, S.J., Duance, V.C., and Mason, D.J. Does protein kinase $\mathrm{R}$ mediate TNF-alpha- and ceramide-induced increases in expression and activation of matrix metalloproteinases in articular cartilage by a novel mechanism? Arthritis Res Ther 6, R46, 2004.

21. Farndale, R.W., Buttle, D.J., and Barrett, A.J. Improved quantitation and discrimination of sulphated glycosaminoglycans by use of dimethylmethylene blue. Biochim Biophys Acta 883, 173, 1986.

22. Singhrao, S., Cole, G., Henderson, W.J., and Newman, G.R. LR White embedding allows a multi-method approach to the analysis of brain tissue from patients with Alzheimer's disease. Histochem J 22, 257, 1990.

23. Darling, E.M., and Athanasiou, K.A. Rapid phenotypic changes in passaged articular chondrocyte subpopulations. J Orthop Res 23, 425, 2005.

24. Frye, S.R., Yee, A., Eskin, S.G., Guerra, R., Cong, X., and McIntire, L.V. cDNA microarray analysis of endothelial cells subjected to cyclic mechanical strain: importance of motion control. Physiol Genomics 21, 124, 2005.

25. Ellis, A.J., Curry, V.A., Powell, E.K., and Cawston, T.E. The prevention of collagen breakdown in bovine nasal cartilage by TIMP, TIMP-2 and a low molecular weight synthetic inhibitor. Biochem Biophys Res Commun 201, 94, 1994.
26. Vaughan-Thomas, A., Gilbert, S.J., and Duance, V.C. Elevated levels of proteolytic enzymes in the aging human vitreous. Invest Ophthalmol Vis Sci 41, 3299, 2000.

27. Moretti, M., Wendt, D., Schaefer, D., Jakob, M., Hunziker, E.B., Heberer, M., and Martin, I. Structural characterization and reliable biomechanical assessment of integrative cartilage repair. J Biomech 38, 1846, 2005.

28. DiMicco, M.A., Waters, S.N., Akeson, W.H., and Sah, R.L. Integrative articular cartilage repair: dependence on developmental stage and collagen metabolism. Osteoarthritis Cartilage 10, 218, 2002.

29. Roach, H.I., Aigner, T., and Kouri, J.B. Chondroptosis: a variant of apoptotic cell death in chondrocytes? Apoptosis 9, 265, 2004.

30. DiMicco, M.A., and Sah, R.L. Integrative cartilage repair: adhesive strength is correlated with collagen deposition. J Orthop Res 19, 1105, 2001.

Address correspondence to: Sophie J. Gilbert, Ph.D.

Connective Tissue Biology Laboratories School of Biosciences Cardiff University Museum Avenue Cardiff, CF10 3US

Wales

United Kingdom

E-mail: gilbertsj1@cardiff.ac.uk

Received: June 27, 2008

Accepted: November 4, 2008

Online Publication Date: January 2, 2009 

Reproduced with permission of the copyright owner. Further reproduction prohibited without permission. 